OPEN ACCESS

Edited by:

Ronny Scherer,

Centre for Educational Measurement at the University of Oslo (CEMO),

Norway

Reviewed by:

Carlos J. Gomez-Ariza, Universidad de Jaén, Spain

*Correspondence: Asghar Iran-Nejad airan-ne@ua.edu

Specialty section:

This article was submitted to Educational Psychology, a section of the journal

Frontiers in Education

Received: 08 December 2016 Accepted: 10 March 2017 Published: 03 April 2017

Citation:

Iran-Nejad A and Irannejad AB (2017)

Commentary: Does Mindfulness Enhance Critical Thinking? Evidence for the Mediating Effects of Executive

Functioning in the Relationship between Mindfulness and Critical

Thinking.

Front. Educ. 2:8

doi: 10.3389/feduc.2017.00008

\section{Commentary: Does Mindfulness Enhance Critical Thinking? Evidence for the Mediating Effects of Executive Functioning in the Relationship between Mindfulness and Critical Thinking}

\author{
Asghar Iran-Nejad ${ }^{1 *}$ and Auriana B. Irannejad ${ }^{2}$ \\ 'Department of Educational Studies in Psychology, Research Methodology, and Counseling, The University of Alabama, \\ Tuscaloosa, AL, USA, ${ }^{2}$ Department of Psychology, The University of Alabama at Birmingham, Birmingham, AL, USA
}

Keywords: self-regulation, executive functioning, conceptual understanding, biofunctional understanding, mindfulness, meditation, observing, non-reactivity

A commentary on

Does mindfulness enhance critical thinking? Evidence for the mediating effects of executive functioning in the relationship between mindfulness and critical thinking by Noone, C., Bunting, B., and Hogan, M. J. (2016). Front. Psychol. 6, 2043. doi: 10.3389/fpsyg.2015.02043

\section{THE ROCKY PATH OF SIMPLIFYING CONTRIBUTIONS BY INTEGRATION}

Does mindfulness (M) enhance critical thinking (CT)? Asks the target article (TA) and dives into physical science's methodology for systematic observation, its binary process of if-then hypothesis testing aimed at confirming or rejecting the null hypothesis that $\mathrm{M}$ enhances $\mathrm{CT}$, and its cause-effect offspring variously known as factual, declarative, or "knowthat" knowledge. This commentary illustrates, with the apt example of the TA, why the methodology does not apply, as readily as it is commonly employed, to life sciences like education and psychology. Binary if-then questions are, as a set, an indispensable tool for simplifying complexity by isolating sources of contribution to make those sources more observable, a tool less rewarding for the unobservable biofunctional systems that populate life sciences. To solve their systematic observation problems, biofunctional life scientists must embrace the rocky path of getting well acquainted with another set of questions and learn to use it corequisitely with the first, and we may be quick to add, both conceptually and biofunctionally (Iran-Nejad and Irannejad, 2017). The second question set contrasts dramatically with the first in that it simplifies complexity in science by integration of multiple diverse sources-a process we use here synonymously with understanding. Specifically, the second set of questions has to do with the all too familiar "how," mainly, but also "why" and similar forms of question.

It is straightforward to show how the two sets of questions and their answers can be corequisites and as such a challenge to the TA. Consider the declarative conceptual understanding statement, CU1 I know that I am mindful to think critically. CU1 is an almost contributor-to-contributor match to the subtitle of the TA in three sources of contribution, namely, the active "I" or the executive function (EF), M, and CT. However, CU1, but not the subtitle, presupposes a fourth source of 
contribution, a tacit corequisite to the other three, so deeply tacit to be taken for granted and fall readily off the wagon, as it did in the title, subtitle, and the rest of the TA. This tacit corequisite source of contribution is the "knowhow" that is the answer to the simplifying by integration "how" question that is so fundamental in biofunctional life sciences. The tacit corequisite relation should be evident by comparing CU1 and CU2 I know that I am mindful to think critically and I know how to be mindful to think critically. Without knowing how, one cannot be mindful to think critically. For similar biofunctional understanding examples, see IranNejad and Irannejad (2017).

\section{SIMPLIFICATION BY ISOLATION IN LIFE SCIENCES}

The central theme of this commentary is that the TA left out critical corequisite sources of contribution, something that happens all too often in both psychology and education. As expected, the binary if-then question in TA's title simplified the sources of contribution in favor of the relatively more observable declarative knowledge at the expense of the corequisite sources of contribution for simplifying by integration. There is evidence that the declarative knowledge that is left over, isolated, and stranded away from its corequisite roots in conceptual and biofunctional understanding amounts to inert knowledge that resists productive integration, transfer, and application to new settings, something that is all too widespread in psychology and education (Bereiter and Scardamalia, 1985; Renkl et al., 1996; Bransford and Schwartz, 1999; Hale, 2013). This explains, though the details are beyond the space of this paper, why the TA's otherwise admirable goals - of (a) mutually inclusive unity in diversity of contribution sources, (b) diversity in coherent unity among corequisite sources of contribution, and (c) CT clarity without entanglement in the binary maze of ambiguity-could not be achieved. Accordingly, out of the five promising facets of $M$ considered, three had to be dropped, one reached an affirmative answer (observing), and one met with a confusing negative answer (non-reactivity). The affirmative finding pertained exclusively to declarative sources, where the EF was shown to mediate significantly the relation between M and CT. However, sadly, there was also a significant negative effect relating $M$ to CT that was not mediated by EF, leading authors to conclude that the "relationship is complex as the non-reactivity facet of $\mathrm{M}$ appears to have a competing negative effect on CT through as yet unidentified mediators" (p. 13).

\section{REFERENCES}

Ahuna, K. H., Innesz, C. G., and VanZile-Tamsen, C. (2011). "Methods of Inquiry": using critical thinking to retain students. Innov. High. Educ. 36, 249-259. doi:10.1007/s10755-010-9173-5

Ahuna, K. H., and Tinnesz, C. G. (2006). Methods of Inquiry: Applied Critical Thinking. Dubuque, IA: Kendall/Hunt.

Bereiter, C., and Scardamalia, M. (1985). "Cognitive coping strategies and the problem of "inert knowledge"', in Thinking and Learning Skills: Current Research and Open Questions, Vol. 2, eds S. F. Chipman, J. W. Segal, and R. Glaser (Hillsdale, NJ: Erlbaum), 65-80.

\section{SIMPLIFYING BY INTEGRATION OF COREQUISITE SOURCES}

As a final say, the TA brought up the need for future research to show if $\mathrm{M}$ improves $\mathrm{CT}$ in education, but never mentioned the substantial volume of existing research. Stretching over three decades before the publication of the TA, many journal articles were reported, not to mention technical reports, dissertations, and books, on the contribution of mindful-plus-corequisite sources of contribution to both achievement and CT in undergraduate education alone. In one line of research, undergraduates responded naturalistically and/or applied in intervention a dynamic-plus-active learning inventory (DALI, see Schapiro and Livingston, 2000; Ahuna and Tinnesz, 2006; Tinnesz et al., 2006; Ahuna et al., 2011). An example for the active (or mindful) subscale was I organize my class notes to consist mainly of the important concepts, definitions, and examples from class and readings. An example for the dynamic (or corequisite) subscale was When I study, what keeps me going is mostly curiosity and interest. Among others, Schapiro and Livingston (2000) reported alpha coefficients of 0.81 for the active and 0.77 for the dynamic subscales at pre-intervention and 0.83 and 0.78 , respectively, at post-invention. The surprising finding that caught the attention of the investigators who had predicted it was that there was no unique contribution of $\mathrm{M}$ without its corequisites. Corequisite sources, on the other hand, accounted alone for the entire volume of the contribution in the data. Intriguingly, these findings are consistent with the definition of meditation as the unbiased cultivation of $\mathrm{M}$ or "the non-judgmental awareness of experiences in the present moment" (Hölzel et al., 2011, p. 537) and that of the non-reactivity facet that mediated negatively between $\mathrm{M}$ and $\mathrm{CT}$ in the TA. Similar findings have been reported in student-centered education (Bransford et al., 2000; McCombs, 2001), person-centered therapy (Rogers, 1951), and first-person education (Iran-Nejad et al., 2015). In all of these, a multiplesource biofunctional system of subsystems unifying a savvy contribution-allocating EF and the flock of its contributiondelegating corequisites seems to be working together in optimal mutual inclusion (Iran-Nejad et al., 1990; Caligiore et al., 2016).

\section{AUTHOR CONTRIBUTIONS}

AI drafted the article first. ABN reviewed and revised it. This cycle repeated for several drafts until the manuscript reached the submitted draft.

Bransford, J. D., Brown, A. L., and Cocking, R. R. (eds) (2000). How People Learn: Brain, Mind, Experience, and School. Washington, DC: National Academy Press.

Bransford, J. D., and Schwartz, D. L. (1999). "Rethinking transfer: a simple proposal with multiple implications," in Review of Research in Education, Vol. 24, eds A. Iran-Nejad and P. D. Pearson (Washington, DC: American Educational Research Association), 1-19.

Caligiore, D., Pezzulo, G., Baldassarre, G., Bostan, A. C., Strick, P. L., Doya, K., et al. (2016). Consensus paper: towards a systems-level view of cerebellar function: the interplay between cerebellum, basal ganglia, and cortex. Cerebellum 16, 203-229. doi:10.1007/s12311-016-0763-3 
Hale, E. (2013). From inert knowledge to activated knowledge: practical ideas for improving student learning. Philos. Study 3, 312-323.

Hölzel, K., Lazar, S. W., Gard, T., Schuman-Olivier, Z., Vago, D. R., and Ott, U. (2011). How does mindfulness meditation work? Proposing mechanisms of action from a conceptual and neural perspective. Perspect. Psychol. Sci. 6, 537-559. doi:10.1177/1745691611419671

Iran-Nejad, A., and Irannejad, A. B. (2017). Conceptual and biofunctional embodiment: a long story on the transience of the enduring mind. Front. Psychol. 7:1900. doi:10.3389/fpsyg.2016.01990

Iran-Nejad, A., McKeachie, W. J., and Berliner, D. C. (1990). Toward a unified approach to learning as a multisource phenomenon (Special Issue). Rev. Educ. Res. 60.

Iran-Nejad, A., Stewart, W., and Robinson, C. (2015). First-person educational psychology for teacher education majors: a spontaneous biofunctional understanding intervention. Int. J. Educ. Psychol. 4, 252-279. doi:10.17583/ijep.2015.896

McCombs, B. L. (2001). What do we know about learners and learning? The learner-centered framework: bringing the educational system into balance. Educ. Horiz. 79, 182-193.

Renkl, A., Mandl, H., and Gruber, H. (1996). Inert knowledge: analyses and remedies. Educ. Psychol. 31, 115-121. doi:10.1207/s15326985ep3102_3
Rogers, C. R. (1951). Client-Centered Therapy. London: Constable.

Schapiro, S. R., and Livingston, J. A. (2000). Dynamic self-regulation: the driving force behind academic achievement. Innov. High. Educ. 25, 23-35. doi:10.102 3/A:1007532302043

Tinnesz, C. G., Ahuna, K. H., and Kiener, M. (2006). Toward college success: internalizing active and dynamic strategies. Coll. Teach. 54, 302-306. doi:10.3200/ CTCH.54.4.302-306

Conflict of Interest Statement: The authors declare that the research was conducted in the absence of any commercial or financial relationships that could be construed as a potential conflict of interest.

Copyright (c) 2017 Iran-Nejad and Irannejad. This is an open-access article distributed under the terms of the Creative Commons Attribution License (CC $B Y)$. The use, distribution or reproduction in other forums is permitted, provided the original author(s) or licensor are credited and that the original publication in this journal is cited, in accordance with accepted academic practice. No use, distribution or reproduction is permitted which does not comply with these terms. 